\title{
Léxico e sociedade. A propósito dos termos de parentesco na Xeografía lingüística galega
}

\author{
Lexicon and Society. On Kinship Terms in Galician Linguistic \\ Geography
}

\author{
Noelia Estévez Rionegro \\ Universidade de Vigo \\ noelia.estevez.rionegro@uvigo.es \\ VERÓNICA RÚA GARRIDO \\ Universidade de Vigo \\ veronica.rua@xunta.gal
}

Recibido: marzo 2020. Aceptado: abril 2020

\begin{abstract}
Resumo: A partir de datos extraídos do Atlas Lingüístico Galego (proxecto de Xeografía lingüística desenvolvido no Instituto da Lingua Galega da Universidade de Santiago de Compostela) relativos ao léxico referido ás relacións de parentesco, analizaranse os valores semánticos denotativos e connotativos dos termos, e amosarase como reflicten o sesgo que presenta a lingua galega canto ao tratamento do masculino e o feminino en función do pensamento ancorado na sociedade. Deste xeito, tratará de amosarse un retrato sociolingüístico da dialectoloxía galega, aplicando conceptos da Análise do Discurso sobre unha base documental pensada para a Dialectoloxía.
\end{abstract}

Palabras chave: Xeografía Lingüística, Léxico de parentesco, Análise do discurso.

Abstract: Some data extracted from the Atlas Lingüístico Galego (a project of Linguistic Geography developed at the Instituto da Lingua Galega of the University of Santiago de Compostela) related to the lexicon that refers to kinship, we will analyze the denotative and connotative semantic values of the terms, and we will show how they reflect the bias that the Galician language presents regarding the treatment of the masculine and feminine genders according to the thought embedded in society. In this way, a sociolinguistic portrait of Galician dialectology will be drawn by applying concepts from Discourse Analysis on a database designed for Dialectology. 
Keywords: Linguistic Geography, Kinship Lexicon, Discourse Analysis.

\section{I.- INTRODUCIÓN}

Non deixa de chamar a atención o feito de que, en comunidades como Galicia, malia existir unha certa tradición matriarcal causada pola emigración masculina, esta non tivera forza suficiente para eliminar o machismo da lingua. Como é obvio, os trazos machistas na linguaxe non son exclusivos da sociedade galega tradicional, senón que permaneceron firmes (e seguen estando presentes, aínda que de xeito, quizais, máis sutil) ao longo dos séculos, e amosan diafanamente a inferioridade coa que se trataba as mulleres nas distintas relacións que estas establecían coa sociedade, co mundo que as rodeaba e coas súas xentes. As condicións de desvantaxe, no caso de Galicia, estaban moi presentes tanto na construción da sociedade en xeral como na propia mentalidade das mulleres, e abarcaban dende os traballos que se realizaban dentro da comunidade até as súas relacións máis íntimas.

O presente traballo xorde como un estudo que pretende abarcar un eido un tanto esquecido nos traballos ou análises sobre a lingua galega: a construción do discurso da muller en galego en base á mesma lingua; pois, a través deste e doutros produtos culturais humanos, pódense identificar as condutas e pensamentos que rexían a sociedade galega dos anos setenta e que amosan como a lingua contribúe, tanto a nivel individual como colectivo, a afianzar uns valores e unhas pautas vitais determinadas, froito da maneira particular en que os falantes vían a realidade e entendían o mundo. É posible atopar abordaxes a este tema desde o punto de vista discursivo, que analizan textos literarios, tanto de autor como populares, mais o que aquí se propón é intentar levar a cabo unha análise completamente aséptica a partir dos datos extraídos dun amplo traballo de investigación en Xeografía Lingüística: o Atlas Lingüístico Galego.

O Atlas Lingüístico Galego é un proxecto fundacional do Instituto da Lingua Galega da Universidade de Santiago de Compostela. O material sobre o que se elaborou o ALGa confórmano as enquisas que os investigadores Rosario Álvarez Blanco, Francisco Fernández Rei e Manuel González González realizaron entre 1974 e 1976 en 167 puntos do territorio de fala galega: Galicia (152), Asturias (7), León (5) e Zamora (3). O cuestionario base deste estudo de campo contén 2711 preguntas que teñen como obxectivo describir as variedades xeográficas do galego moderno, pero que tamén tratan de ofrecer unha visión da realidade que permita a comparación con outros dominios. Desde a súa orixe, o proxecto do $A L G a$ estivo vencellado con outras empresas do campo da Xeografía Lingüística que atenden a dominios xeolingüísticos máis amplos, polo que o referido cuestionario inclúe as preguntas do Atlas Lingüístico de España e Portugal e do Atlas Linguarum Europae. Co material recollido creouse unha base de datos de case medio millón de rexistros na que se inclúe o texto das respostas e abundante información complementaria. A conexión entre a base de datos e un programa de xestión de información xeográfica permite a representación cartográfica inmediata de cada unha das respostas do cuestiona- 
rio. Até a actualidade apareceron cinco volumes: Morfoloxía verbal; Morfoloxía non verbal; Fonética; Léxico. Tempo atmosférico e cronolóxico; e Léxico. $O$ ser humano (I). Porén, o corpus léxico que presentamos a continuación, soporte empírico do noso estudo, foi extraído dun terceiro volume léxico adicado tamén ao ser humano (volume II) que aínda está por publicar. Centramos a nosa análise naquela información significativa que permite avaliar o sesgo que a lingua galega presenta canto ao tratamento do masculino e do feminino como reflexo da sociedade e que configura o eixe sobre o que xira o presente traballo: o léxico referido á familia e ás relacións de parentesco.

O estudo dos datos cos que contamos permite ver e analizar certas cuestións relevantes sobre a selección do léxico que realizan os falantes para designar as mesmas realidades parentais en homes e en mulleres e as connotacións sociolingüísticas que delas se tiran. Trala pertinente análise dos termos de parentesco, centrarémonos neste traballo no léxico que clasificamos baixo as seguintes taxonomías: estruturación da sociedade segundo a idade e estruturación da sociedade segundo o parentesco.

\section{II.- ESTRUTURACIÓN DA SOCIEDADE SEGUNDO A IDADE}

A partir dos datos extraídos das cuestións tratadas nas enquisas, podemos establecer unha clasificación en relación á estruturación da sociedade segundo a idade conformada por catro períodos ben diferenciados entre si e representados por formas, como veremos, moi significativas:

- Período infantil: neno/a

- Preadolescencia e adolescencia: rapaz/a (de 12 a 17 anos)

- Postadolescencia: mozo/a

- Idade adulta: muller feita de 25 anos en adiante

\subsection{Período infantil: neno/a}

Este período caracterízase, principalmente e en comparación cos rangos de idade que trataremos máis adiante, por unha maior ausencia de connotacións entre as formas masculinas e as femininas, sendo moi frecuentes, en ambos os dous casos, formas que presentan sufixos afectivos (-iño, -iña, -ín, -ía) e que se explican polo significado evocado do concepto polo que se pregunta. Existen abundantes exemplos deste feito en todo o territorio:

- neniño- neniña

- nenín- nenía

- meniño- meniña

- rapaciño- rapaciña 
No entanto, si se poden observar, por outra banda, termos que presentan certos sufixos aumentativos unicamente presentes nas formas léxicas masculinas e que indican superioridade, xa sexa de idade ou tamaño, fronte ás formas femininas, que en ningún caso presentan este tipo de sufixación. Este feito lingüístico tan relevante garda certa relación co concepto feminista da «eterna minoría de idade» que tradicionalmente se lle presupón ás mulleres.

Exemplo das formas masculinas con sufixación aumentativa son as que presentamos a seguir:

- rapacete: forma recollida en Santa Comba (Lugo).

- rapazote: rexistrouse en Elviña (A Coruña), Camariñas (A Coruña), Mesía (A Coruña), Sobrado (A Coruña), Fisterra (A Coruña), Avión (Ourense), Larouco (Ourense) e en Cotobade (Pontevedra).

- mocete: aparece rexistrada en Pontedeume (A Coruña), Monfero (A Coruña), Aranga (A Coruña), Vilasantar (A Coruña), Sobrado (A Coruña), Trabada (Lugo), Becerreá (Lugo) e en Vila de Cruces (Pontevedra).

\subsection{Preadolescencia e adolescencia: rapaz/a (de 12 a 17 anos)}

Nunha primeira análise superficial destaca nesta franxa de idade, a respecto da anterior, un aumento moi significativo das formas masculinas fronte ás femininas (32 formas masculinas fronte a 13 ocorrencias femininas).

Ademais, as formas masculinas que non teñen correspondencia coas femininas presentan, novamente, sufixos aumentativos referidos xa no período infantil:

- rapazote: (Vid. período infantil)

- rapazón: : rexistrouse en Sobrado e Santiso, ambos concellos na provincia da Coruña.

- chavalote: recollida en Baleira (Lugo), Vilamartín de Valedoras (Ourense), Larouco (Ourense), Baños de Molgas (Ourense), Castrelo do Val (Ourense) e en Forcarei (Pontevedra).

- mangallón: recolleuse en Boiro (A Coruña).

- gallote: aparece rexistrada en Rodeiro (Pontevedra).

- cascote : foi recollida en Vilasantar (A Coruña), Santiago de Compostela (A Coruña), Santiso (A Coruña), Moaña (Pontevedra), Ponteareas (Pontevedra) e en A Veiga (Asturias).

Canto ao significado dos rexistros atopados, tamén se observan importantes diferenzas entre as formas masculinas e femininas de tipo conceptual referidas á idade: un neno faise rapaz antes ca unha nena. 
Na maior parte dos puntos onde se recolle este tipo de información, considérase unha muller rapaza ao ter cumpridos, como mínimo, 13 anos (nalgún punto, como en Rianxo (A Coruña), a partir dos 15 anos):

- En Navia de Suarna (Asturias): rapaceta «aos 14 anos»

- En O Pereiro de Aguiar (Ourense): rapaza «de 13 a 14 anos»

- En Ponteareas (Pontevedra): rapariga «14 anos».

- En Ibias (Asturias): rapazapa «12-13 anos»

No caso das formas que se refiren a rapaz, na maioría dos puntos do territorio é moi anterior o paso dun estadio a outro (de neno a rapaz). Vexamos unha pequena mostra disto:

- En Sada (A Coruña): rapaz «de 9 a 10 anos»

- En Monfero (A Coruña): rapaz «de 6 anos en adiante»

- En Laxe (A Coruña): rapaz «a partir dos 8 anos aproximadamente»

- En Cerceda (A Coruña): rapaz «de 5 a 12 anos»

- En San Cristovo de Cea (Ourense): rapaz «de 6 anos en adiante»

- En Rivadavia (Ourense): rapaz «de 7 anos en adiante»

- En Vilardevós (Ourense): rapaz «dos 4 anos para adiante»

Como se pode observar, prolóngase considerablemente o período infantil nas mulleres fronte ao dos homes, o que novamente se pode ligar coa «eterna minoría de idade» feminina, de aí que se considere que os pais teñen a postestade sobre elas até que casan e pasa a ser o marido quen a exerce no novo estado civil; prívaselles, polo tanto, da capacidade de decidir, opinar e actuar, como se dunha nena se tratase.

\subsection{Postadolescencia: mozo/a}

No período de idade que tratamos a continuación segue sendo significativa a sufixación aumentativa no caso das formas masculinas e que segue sen estar presente no caso oposto:

- mozote rapazote chavalote

Tamén é relevante a existencia dun maior número de formas masculinas fronte ás ocorrencias dos termos femininos, que tan só rexistran catro formas:

- moza mozo (mozote, mocete, mozalbete)

- noiva/ novia noivo/ novio

- rapaza rapaz (rapazote) chaval 


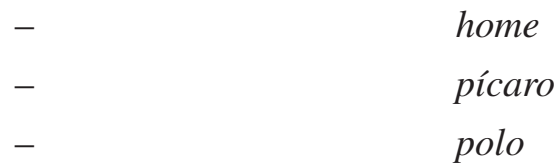

A respecto do significado conceptual que viamos na anterior cuestión, aquí preséntasenos o caso contrario: a muller xa pode ser moza entre os 10 e os 12 anos tal e como se recolle en Tapia de Casariego (Asturias), mentras que o home ten que esperar, cando menos, até os 14, aínda que na maioría dos puntos onde se recolleu esta información esta categoría acádase moito máis tardiamente:

- En Aranga (A Coruña): mozo «20 anos»

- En Sobrado (A Coruña): mozalbete «de 16 anos en adiante»

- En Sober (Lugo): mozo «aos 20 anos»

- En O Grove (Pontevedra): mozo «18-19 anos»

- En Baños de Molgas (Ourense): mozo «cando se mide para o servizo militar»

Destes datos e dos anteriores podemos deducir doadamente que a muller se considera nena moito máis tempo ca o home (isto é, «máis pequena», en todos os sentidos) pero que, ao mesmo tempo, pode pasar —e, de feito, pasaba- a alcanzar a categoría de moza (a plena adolescencia) moito antes ca o rapaz, asumindo responsabilidades dunha muller practicamente adulta (sempre relacionadas co matrimonio, co coidado da familia ou co traballo na casa; pero nunca con actividades intelectuais).

\subsection{Idade adulta: muller feita de 25 anos en adiante}

Considerablemente significativas son a maioría das formas recollidas no territorio para designar a muller a partir dos 25 anos de idade mais, sen deternos nunha análise profunda, limitarémonos a expoñer brevemente a clasificación destas formas que, por outra banda, son unha clara mostra dos prexuízos que imperaban na sociedade galega do momento.

Agrupamos os termos recollidos baixo diferentes epígrafes que responden a características lingüísticas comúns en todos eles:

- Formas neutras:

- moza (19 ocorrencias)

- muller (9 ocorrencias)

- rapaza (2 ocorrencias)

- Formas con connotación sufixal:

Sufixos aumentativos (connotación negativa: «demasiada idade»)

- mozona: aparece recollida en San Amaro (Ourense). 
- mullerona: rexistrouse en Ares (A Coruña).

- solteirona: é forma maioritaria, recolleuse en 62 puntos do territorio de fala galega, referenciamos algúns a modo de exemplo: en Pontedeume (A Coruña), Sobrado (A Coruña), Toques (A Coruña), Touro (A Coruña), Muros (A Coruña), O Valadouro (Lugo), Vilalba (Lugo), Cervantes (Lugo), O Incio (Lugo), Chandrexa de Queixa (Ourense), Baños de Molgas (Ourense), Padrenda (Ourense), A Estrada (Pontevedra), Bueu (Pontevedra), Moaña (Pontevedra), Arbo (Pontevedra), Salceda de Caselas (Pontevedra), Salvaterra de Miño (Pontevedra), Coaña (Asturias), Boal (Asturias), Vilanova de Oscos (Asturias) ou en Candín (León).

- moza trintona: foi recollida en A Pobra do Brollón e en Carballedo (Lugo).

Tamén se recolleron as formas vellaucona e muller feitona.

- Sufixos diminutivos (connotación negativa «minoría de idade»)

- rapariga: en Vigo, Ponteareas, O Porriño, Arbo, Baiona, Salceda de Caselas, Oia, Tomiño e A Guarda, todos estes puntos na provincia de Pontevedra.

- Formas despectivas que aluden ao «pasamento de idade» e á «perda de certas cualidades ou atributos»

- subs. + cascada

- subs. + resesa

- subs. + refeita

- subs. + madura

- subs. + vella/vellota/ revella/ reviegha

- subs. + feita

- subs. + cumplida/ cumprida

Dentro deste epígrafe tamén se fai alusión á proximidade aos 30 anos:

- trintenal trinteña

- Formas despectivas que aluden ao non-casamento (unha das funcións principais atribuídas á muller da época)

- subs. + quedada

- subs. + celibata

- subs. + solteira

A maioría destas formas, como se pode observar, ratifican unha concepción patriarcal predominante no momento: o matrimonio como situación «ideal» para a muller da época, penalizando lexicamente camiños alternativos a este 
estado. Unha vez máis atopámonos de maneira clara e directa —especialmente, nos dous últimos apartados - con trazos machistas na linguaxe, reflexo do pensamento que a sociedade tradicional tiña sobre o papel das mulleres na comunidade e das súas obrigacións como tales.

\section{III.- ESTRUTURACIÓN DA SOCIEDADE SEGUNDO O PARENTESCO}

No presente apartado preséntanse os datos obtidos nas enquisas canto ás relacións parentais e os termos empregados polos falantes para designalas. Novamente, atenderemos ás diferenzas léxicas que existen no tratamento do masculino e o feminino dende o propio núcleo familiar.

Establécese a seguinte taxonomía:

- Relacións conxugais

- home / muller

- parente / parenta

- Relacións paternofiliais

Sanguíneas

- pai/nai

Políticas

- padrastro / madrastra

- sogro /sogra

- xenro /nora

- fillastro

- Relacións fraternofiliais

- irmán / irmá

\subsection{Relacións conxugais}

Os resultados das enquisas mostran que existen moitos menos termos e con moitas menos connotacións para referirse ao home, como cónxuxe ou parella, que á muller. Así, a forma predominante, con 158 ocorrencias, é a neutra home. Porén, na parroquia de Santiso, Lalín (Pontevedra) recóllense algúns refráns que resultan altamente significativos, xa que non manteñen esa forma aséptica senón que tratan de manifestar a fortaleza do varón e os traballos que lle son propios, revelándoo como unha figura de autoridade:

- Home escopeteiro nin meda nin palleiro

- Na terra do meu home o que non traballa non come 
Atópanse outras tres formas, aínda que con menos ocorrencias que a anterior:

- marido: rexistrada na Pastoriza (Lugo), Cospeito (Lugo), Láncara (Lugo), O Incio (Lugo), Pobra do Brollón (Lugo), Boborás (Ourense), O Porriño (Pontevedra) e Porto de Sanabria (Zamora).

- paisano: en Cospeito (Lugo), Monfero (A Coruña) e Corullón (León).

- mozo: en Forcarei (Pontevedra)

Ningunha delas presenta connotacións de ningún tipo canto á morfoloxía ou á semántica. Trátase de termos asépticos cos que referirse unicamente á relación conxugal, sen valoracións positivas nin negativas. No entanto, existe unha excepción en A Pobra de San Xiao, Láncara (Lugo) onde se recolle o termo patrón co significado de «xefe da casa», forma evidentemente machista pero pouco frecuente no resto da xeografía galega.

Pola súa parte, os termos empregados para referirse á esposa son moito máis abondosos e connotativos. A forma predominante é, tamén, a neutra muller, con 166 ocorrencias. Existe unha excepción canto á asepticidade do termo en Sabarís, Santa Cristina de Ramallosa (Pontevedra), onde a forma se emprega cun matiz semántico referido á esposa dun matrimonio no que existe unha separación de bens.

Menos frecuentes son outros termos neutros como:

- paisana (con referente masculino paisano): en Trabada (Lugo), A Pastoriza (Lugo), Cospeito (Lugo), Larouco (Ourense), Montederramo (Ourense), A vión (Ourense), Boborás (Ourense), Vilardevós (Ourense), Forcarei (Pontevedra), Monfero (A Coruña), Corullón (León).

- marida (con referente masculino marido)

- señora: en Boborás (Ourense)

- compañeira

- dona

Porén, xunto a estas formas, rexístranse outras con connotacións semánticas desprezativas cara á muller. Moi significativas son as formas léxicas costela e costilla que, con clara referencia bíblica (costela de Adán), refiren a pauta cristiá e patriarcal coa que se estruturaba a sociedade. Trátase, ademais, de termos dos que non existe un referente masculino, o que redunda no contido sexista da palabra.

Aínda que só está rexistrada nun caso, resulta interesante a forma cómbara, derivada de cómbaro, substantivo que designa o muro que bordea e protexe un terreo servindo de linde para fincas colindantes. A asociación de significados parece un tanto arriscada mais podería entenderse á esposa como elemento protector e amparador do fogar, que marca os límites da institución matrimonial.

- Parente - parenta 
Neste caso, só se rexistran as variantes galega e castelá para referirse tanto ao marido como á esposa:

- parente: forma predominante nas provincias de Lugo e Ourense, no centro-oeste da Coruña e o sur de Pontevedra.

- pariente: rexistrada no sur da Coruña e o norte de Pontevedra (nas zonas limítrofes).

- parenta: forma predominante nas provincias de Lugo e Ourense, no centro-oeste da Coruña e o sur de Pontevedra.

- parienta: rexistrada no sur da Coruña e o norte de Pontevedra (nas zonas limítrofes).

A única diferenza de significado entre o referente masculino e o feminino é que no primeiro caso a palabra pode designar, nalgúns puntos xeográficos (como Santa Comba, A Coruña), ao curmán, ademais do cónxuxe, mentres que en feminino só se recolle como referente matrimonial.

\subsection{Relacións paternofiliais}

\subsubsection{Sanguíneas (pai-nai)}

De igual xeito que no apartado anterior, rexístranse máis termos para referirse á proxenitora ca ao proxenitor. Da forma masculina destaca en frecuencia pai, mais atopamos as seguintes variantes léxicas:

- meu pai: recollido en Moeche (A Coruña).

- padre: rexistrado en Valdoviño (A Coruña), Ares (A Coruña), O Valadouro (Lugo), Trabada (Lugo), A Pontenova (Lugo), Guitiriz (Lugo), Cervantes (Lugo), O Incio (Lugo), Chandrexa de Queixa (Ourense), Tapia de Casariego (Asturias), Coaña (Asturias), A Veiga (Asturias), Boal (Asturias), Vilanova de Oscos (Asturias), Pesoz (Asturias), Ibias (Asturias), Candín (León), Vilafranca do Bierzo (León), Corullón (León), Carracedelo (León) e Hermisende (Zamora).

- meu padre: en Moeche (A Coruña), Vimianzo (A Coruña), A Estrada (Pontevedra) e Folgoso do Courel (Lugo).

- mi padre: en Ribadeo (Lugo) e negreira de Muñiz (Lugo).

Como se pode observar, existe un forte predominio da forma castelá, lingua considerada de maior autoridade e respecto. Deste xeito, a figura paterna eríxese como símbolo de potestade, dominio e supremacía, fronte á figura materna para a que predominan os termos galegos, lingua da intimidade e a familiaridade. Os matices semánticos entre o referente masculino e o feminino parecen establecerse en función do respecto e poder e a confianza e afectividade. No entanto, cómpre destacar que nalgúns lugares como Seoane do Caurel (Lugo) os propios informantes recoñecen que os termos de autoridade están xa caídos 
en desuso, o que revela unha certa evolución positiva da antiga estruturación patriarcal da sociedade.

Ao lado dos termos femininos nai, mai, miña nai e miña mai, achamos outros (formados morfoloxicamente a través dun proceso de iteración lexemática) como:

- nanai: recollido en Rodeiro (Pontevedra) e Muros (A Coruña).

- mamai: en Vigo (Pontevedra).

- mamá: en Muros (A Coruña), Vigo (Pontevedra) e Folgoso do Courel (Lugo),

O referente feminino non está, porén, exento dos termos de autoridade, aínda que as ocorrencias son inferiores ás correspondentes en masculino:

- madre: en Ares (A Coruña), Sada (A Coruña), Vilasantar (A Coruña), Chandrexa de Queixa (Ourense), Rubiá (Ourense), Carballeda de Valdeorras (Ourense), Cervantes (Lugo), O Incio (Lugo), Trabada (Lugo), A Pontenova (Lugo), O Valadouro (Lugo), Tapia de Casariego (Asturias), Coaña (Asturias), A Veiga (Asturias), Boal (Asturias), Vilanova de Oscos (Asturias), Pesoz (Asturias), Ibias (Asturias), Candín (León), Vilafranca do Bierzo (León), Corullón (León), Carracedelo (León) e Hermisende (Zamora).

- miña madre

- mi madre

\subsubsection{Políticas (padrasto - madrasta)}

A respecto da relación paternofilial co compañeiro/a do pai/nai, tamén se dá unha importante diferenza entre os termos referidos ao home e aqueles que aluden á muller. Aínda que, en ambos os casos, as palabras presentan derivacións morfolóxicas despectivas a través do emprego de sufixos con connotacións pexorativas, no caso do referente feminino rexístranse formas que chegan a ser ofensivas; non así no masculino.

Se ben o termo masculino máis abondoso é padrasto, xunto coas variantes padrastro, padastro e padasto, atopamos outras formas máis desprezativas como padastío e padrasco. Incluso, recolleuse a palabra tío con este significado, o cal afasta a relación paternofilial e establece outra dun grao inferior na liña de parentesco (tío-sobriño como marca diferencial entre pai e fillo propio - sanguíneo- e pai e fillo alleo - non sanguíneo-). É interesante, tamén, o sintagma recollido en Muras (Lugo) para designar este tipo de relación: parentes indefinidos, que alude explicitamente a unha lagoa conceptual para designar un tipo de relación pouco habitual e non moi ben vista no contexto social da época.

Todos os termos masculinos teñen o seu correspondente en feminino: sendo maioritarias as formas madrasta, madrastra, madastra, madasta, recóllense, tamén, madastía e madrasca; ademais, de tía. Porén, contrariamente ao caso 
masculino, no feminino rexístrase en Dodro (Vigo) o termo puta para aludir á esposa do pai; forma oprobiosa que non atopa ningún correspondente semellante no referente masculino.

Canto á relación á inversa, é dicir, dende o punto de vista do fillo non sanguíneo, a representación léxico-semántica do pensamento é practicamente idéntica á anterior, mais un ápice máis afectiva. As formas predominantes son fillastro e fillasto e, ao seu carón, seguen a aparecer sufixacións altamente despectivas como:

- fillarasco

- fillasco: en Ponteceso (A Coruña).

Do mesmo xeito, rexístrase a forma sobriño no mesmo sentido que tío e tía, mais emerxe o termo primo carnal que afasta un grao máis a relación de parentesco. Resulta, neste caso, un tanto paradoxal o feito de empregar o adxectivo carnal referido á consanguinidade, caracterizándose a relación precisamente polo contrario.

No entanto, existe un eco positivo neste aparente proceso de afastamento do parentesco recollido na forma fillo, con máis ocorrencias que algunhas despectivas das anteriormente vistas.

- Sogro-sogra

Neste caso existe unha maior neutralidade que nos anteriores. Recóllense equitativamente os termos sogro e suegro para o masculino e sogra e suegra para o feminino. En Oímbra (Lugo) aparecen, ademais, as formas afectivas abuelo e abuela que achegan a relación política á sanguínea.

A única diferenza salientable do referente masculino, a respecto do feminino, rexístrase en Sobrado (A Coruña), onde aparece a forma afectuosa papae sen correspondente en feminino.

No caso da liña inversa, a que sinala a relación dende o punto do fillo político, as diferenzas tampouco son apreciables. Rexístrase para o referente masculino a forma predominante xenro seguido de noro e para o referente feminino nora seguido de xenra. En ambos os casos a forma minoritaria é a que alude ao xénero oposto. Pódese resaltar que, no caso masculino, recóllese en Vimianzo (A Coruña) un sentido especial para o termo noro, aplicado, a xeito de burla, ao futuro xenro ao atoparse diante de quen lle vai ser sogro.

\subsection{Relacións fraternofiliais (irmán - irmá)}

Non existen neste tipo de relacións representacións léxicas demasiado diferentes entre o referente masculino e o feminino. Si cabe destacar, porén, que son máis prolíferas as formas en masculino, pois presentan un número de variantes considerablemente maior:

- irmán: forma predominante nas provincias da Coruña e Pontevedra. 
- ermán: rexistrado na Coruña, Sada (A Coruña), Carral (A Coruña) e Ames (A Coruña).

- Irmá: Valdoviño (A Coruña), Aranga (A Coruña) e Guitiriz (Lugo).

- irmao, irmau: forma predominante nas provincias de Lugo e Ourense e as zonas nas que estas lindan coa Coruña e Pontevedra.

- ermao, irmau: recollida en Mañón (A Coruña), O Pereiro de Aguiar (Ourense), Trabada (Lugo), Castro de Rei (Lugo), Friol (Lugo), Baleira (Lugo), Guntín (Lugo), Baralla (Lugo), Triacastela (Lugo), Candín (León), Carracedelo (León), Tapia de Casariego (Asturias), Coaña (Asturias), A Veiga (Asturias), Boal (Asturias), Pesoz (Asturias), Ibias (Asturias) e Candín (León).

- irmou: en Lubián (Zamora).

- ermão: en Candín (León).

- ermano: en Ferrol (A Coruña), Ares (A Coruña) e Carracedelo (León).

Fronte aos femininos:

- irmá: forma predominante las provincias de Lugo e Ourense e as zonas lindeiras da Coruña e Pontevedra.

- ermá: rexistrada na Coruña, Mañón (A Coruña), O Pereiro de Aguiar (Ourense), Trabada (Lugo), Castro de Rei (Lugo), Friol (Lugo), Baleira (Lugo), Guntín (Lugo), Baralla (Lugo), Triacastela (Lugo), Tapia de Casariego (Asturias), Coaña (Asturias), A Veiga (Asturias), Boal (Asturias), Pesoz (Asturias), Ibias (Asturias) e Candín (León).

- irmán: forma predominante nas provincias da Coruña e Pontevedra.

- ermán: na Coruña, Sada (A Coruña), Carral (A Coruña) e Ames (A Coruña).

- ermã: en Candín (León).

- ermana: en Ares (A Coruña) e Carracedelo (León).

\section{IV.- CONCLUSIÓNS}

En trazos xerais, no presente traballo tratamos de demostrar de maneira descritiva a enorme carga sexista que presenta a linguaxe, fomentada pola situación social do momento, e que se manifesta en todos os planos da vida cotiá, incluso no máis íntimo: o familiar. A través da recollida e análise do léxico empregado para designar a idade vital e as relacións parentais en todos os puntos da xeografía galega, pódese comprobar que os termos referidos a ambos campos léxicos presentan estritas semellanzas canto ao tratamento do masculino e o feminino no uso que os propios falantes fan da lingua, neste caso, nas súas distintas variantes dialectais. 
En efecto, a linguaxe proporciona unha visión extraordinariamente diáfana do pensamento e a conceptualización da sociedade canto á estruturación da idade, das relacións de parentesco e das relacións sociais en xeral. Á vista dos datos expostos, demóstranse na fala as claras reticencias sociais cara á muller, ao machismo e ao patriarcalismo imperantes na sociedade de todos os tempos. O compoñente pexorativo e despectivo que se extrae dos termos referidos á muller nas súas distintas facetas dentro da comunidade non son máis que o reflexo do pensamento ancorado na sociedade, da categorización en función de xéneros que posiciona o home nun lugar privilexiado mentres a muller se relega a un plano completamente desprestixiado. Fronte ao respecto dialéctico que se lle garda ao home na linguaxe, a muller vese constantemente atacada e agraviada verbalmente, sendo designada con termos instaurados no lexicón dos falantes da lingua e creados en base a unha situación social de machismo e desigualdade, a cal repercute inxustamente na linguaxe e, por suposto, na figura da muller.

\section{BIBLIOGRAFÍA}

Fernández, F. (1990) Dialectoloxía da lingua galega, Vigo, Xerais.

Frías, F. X. (1997) «Sobre os bloques dialectais do galego: unha nova proposta», Revista Filología Románica, 14/1, pp. 241-256.

García, C. + Santamarina, A. + Álvarez, R. + Fernández, F. + González, M. (1990) Atlas Lingüístico Galego. Vol. I: Morfoloxía verbal, A Coruña: Fundación Pedro Barrié de la Maza.

García, C. + Santamarina, A. + Álvarez, R. + Fernández, F. + González, M. (1995) Atlas Lingüístico Galego. Vol. II: Morfoloxía non verbal, A Coruña: Fundación Pedro Barrié de la Maza.

García, C. + Santamarina, A. + Álvarez, R. + Fernández, F. + González, M. (1999) Atlas Lingüístico Galego. Vol. III: Fonética, A Coruña: Fundación Pedro Barrié de la Maza.

García, C. + Santamarina, A. + Álvarez, R. + Fernández, F. + González, M. (2003) Atlas Lingüístico Galego. Vol. IV. Léxico. Tempo atmosférico e cronolóxico, A Coruña: Fundación Pedro Barrié de la Maza.

García, C. + Santamarina, A. + Álvarez, R. + Fernández, F. + González, M. (2005) Atlas Lingüístico Galego. Léxico. Vol. V: O ser humano (I), A Coruña: Fundación Pedro Barrié de la Maza. 